\title{
Head-Marking and Agreement: Evidence from Yucatec Maya ${ }^{1}$
}

\author{
Jürgen Bohnemeyer, Lindsay K. Butler \& T. Florian Jaeger
}

\section{Introduction}

This chapter revisits one of the foundational analyses of Role and Reference Grammar (RRG; cf. Foley \& Van Valin 1984, Van Valin \& LaPolla 1997, Van Valin 1993, 2005, inter alia), according to which in head-marking polysynthetic languages such as Lakhota, the pronominal markers morphophonologically bound to a syntactic head saturate its valency requirements (Van Valin 1977, 1985, 2013). Given the architecture of the Layered Structure of the Clause (LSC), this entails that syntactically optional reference phrases (RPs) coindexed with clausemate bound pronominal argument markers (henceforth, 'cross-reference markers') cannot be core constituents, since cores are by definition constituted by heads (nuclei) and their syntactic arguments. The most recent proposal within RRG places RPs in 'Extra-Core Slots'. These positions are immediate daughters of the clause, but their presence in it is licensed by the occurrence of cross-reference markers on a nucleus (Van Valin 2013).

1 Robert D. Van Valin, Jr., pointed out to us the fit between our data and Bresnan \& Mchombo's proposal. We are grateful for his advice, as well as for that of Kay Bock and Lorena Pool Balam. We would like to thank Randi Tucker for help with the manuscript, and of course the editors for inviting us to contribute and for their patience with us. The material presented in Section 5 is based upon work supported by the National Science Foundation under Grant No. BCS-0848353 and BCS-0848298 Collaborative Research: Studying Language Production in the Field (PIs TFJ and JB). Additional support came from a Dissertation Improvement Grant from SBSRI, University of Arizona to LKB and the Wilmot Award to TFJ. None of the scholars and institutions mentioned bear any responsibility for the content presented here or the form in which it is presented. 
We present two sources of evidence from Yucatec Maya that point to the need for a modification of the above analysis. First, distributional evidence suggests that cross-referenced RPs are not, in fact, immediate daughters of the clause in Yucatec. Specifically, in core cosubordination, in which two cores form a higher core, sharing an operator projection and a periphery, RPs cross-referenced on the first verb may appear between the two verbs. Since Yucatec otherwise lacks discontinuous syntactic projections, this makes direct dominance by the clause implausible.

Secondly, Yucatec is a language with optional number marking on both nouns and verbs. We discuss data from two production experiments on the production of plural marking in Yucatec (first reported in Butler, Jaeger \& Bohnemeyer 2014). In the clear majority of responses, participants marked the cardinality of the set of individuals involved in the stimulus actions on either both the verb and the cross-referenced RP or on neither. We argue that this finding supports an analysis according to which the cross-reference markers fill the syntactic argument positions of the verb in case they are not accompanied by clause-mate RPs, but express agreement with cross-referenced clause-mate RPs when the latter are present. In the second case it is the RPs that saturate the valency of the verb. A similar analysis was proposed by Bresnan \& Mchombo (1987) for the so-called subject markers of Cichewa. This is consistent with the distributional evidence pointing to the cross-referenced RPs being core constituents.

The remainder of the chapter is organized as follows: Section 2 introduces relevant background on the grammar of Yucatec. Section 3 summarizes the analysis of head-marking advanced in Van Valin $(1977,1985,2013)$ in the broader context of the literature on the topic. The following sections present the distributional evidence for cross-referenced RPs not being immediate daughters of the clause (Section 4) and the production evidence for agreement (Section 5). Section 6 offers a discussion of the findings and concludes.

\section{Head-marking in Yucatec}

\subsection{The language and its speakers}

Yucatec is the largest member of the Yucatecan branch of the Mayan language family. It is spoken across the Yucatan peninsula in the Mexican states of Campeche, Quintana Roo, and Yucatán and in the Orange Walk and Corozal districts 
of Belize. Mexican census data from 2005 puts the number of speakers age 5 or older at 759,000 (PHLI 2009). The Ethnologue places an additional 6,000 speakers in Belize as of 2006 (Lewis 2009).

\subsection{Cross-reference marking}

Yucatec is an exclusively head-marking language - there is no nominal case marking of any kind. Like most Mayan languages, Yucatec has two paradigms of morphologically bound pronominal argument or 'cross-reference' markers (following Bloomfield 1933: 191-194). Mayanists have become accustomed to labeling these paradigms 'Set A' and 'Set B'. The arbitrariness of these labels reflects the polyfunctionality of the two sets and the complex and highly variable nature of the argument marking splits found across the Mayan language family. Table 1 summarizes the distribution and functions of the paradigms in Yucatec:

\begin{tabular}{|l|l|l|}
\hline Environment & Set A & Set B \\
\hline Transitive verbs (active voice) & A(ctor) & U(ndergoer) \\
\hline $\begin{array}{l}\text { Intransitive verbs; transitive } \\
\text { verbs in non-active voice }\end{array}$ & S (incompletive 'status') & $\begin{array}{l}\text { S (completive, subjunctive, } \\
\text { extrafocal 'status') }\end{array}$ \\
\hline Other lexical categories & Possessor of nominals & S of non-verbal predicates \\
\hline
\end{tabular}

Table 1: Distribution and functions of the two paradigms of Yucatec cross-reference markers

For illustration, (1) shows two possessed nominal predicates, each carrying the 1SG Set-A marker cross-referencing the possessor and the 2SG Set-B marker cross-referencing the theme.

(1) Síh in=iiho-ech, in=pàal-ech, ko'x! yes A1SG=son-B2SG A1SG=child-B2SG EXHORT

'You ARE my son alright, you ARE my child; let's go!' (Lehmann 1991)

The next example shows the same two cross-reference markers realizing the two arguments of a transitive verb:

(2) T-inw=il-ah-ech te $=h a^{\prime} t s+k a b+k$ 'ìin $=a$ '.

PRV-A1SG=see-CMP-B2SG PREP:DEF=divide:PASS+Earth+sun=D1

'I saw you this morning.'

Lastly, (3)-(4) feature the same transitive matrix verb il 'see' of (2) and a second verb, the unaccusative lúub 'fall'. The argument of the second verb is realized by 
a 2SG cross-reference marker in both cases. In (3), the intransitive verb appears in incompletive status, and consequently, the S-argument is realized by the 2SG Set-A clitic $a=$. This sentence instantiates a direct (i. e., event) perception construction. In contrast, in (4), the intransitive verb appears in completive status and the argument is consequently realized by the 2SG Set-B suffix. In this case, the perception verb is used as a transferred expression of a cognitive inference.
(3) $T$-inw=il-ah a=lúub-ul.
PRV-A1SG=see-CMP(B3SG) A2=fall-INC
'I saw you fall(ing).'
(4) T-inw=il-ah déekeh h-lúub-ech.
PRV-A1SG=see-CMP(B3SG) COMP LPRV-fall-B2SG
'I saw that you fell.'

We treat the cross-reference markers as (nearly) direct expressions of semantic macro-roles rather than of grammatical relations, following Bohnemeyer (2004, 2009a). Following established practice in RRG, we use 'A(ctor)' for the thematically highest-ranked, most agent-like argument of active-voice transitive verb forms, 'U(ndergoer)' for the lower-ranked argument, and 'S' for the single argument of intransitive verbs and the theme of non-verbal predicates. (There are arguably no syntactically ditransitive clauses in Yucatec; recipients of transfer events are expressed by oblique arguments.) The evidence against the crossreference markers expressing grammatical relations can be summarized as follows:

- Intransitive verbs show a split marking pattern - there is thus no uniformly marked subject (Bohnemeyer 2004 and references within; see below);

- Intra-clausal linking is subject to alignment/obviation constraints, which prevent actors from being uniformly linked to a designated argument - the subject - in active voice (Bohnemeyer 2009a);

- Inter-clausal linking is governed by construction-specific rules, which do not submit to an overall characterization in terms of a uniform grammatical 'pivot' - the subject - on which they operate (Bohnemeyer 2009a).

Table 1 and examples (2)-(4) suggest a typologically unusual argument marking split in verbal cores: the S-argument of intransitive cores is realized by Set-A in 'incompletive status', but by Set-B in 'completive', 'subjunctive', and 'extrafocal 
status'. Status is a functional category of the Mayan verb that conflates viewpoint aspect and mood. Incompletive status can be treated as unmarked for both. Historically, it seems to have originated as a nominalization and still functions as such in certain contexts (Bohnemeyer 2002: 157-159, 216-228). Completive status expresses perfective aspect and realis/indicative mood, while subjunctive status can be considered in first approximation an aspectually neutral irrealis mood (Bohnemeyer 2012). 'Extra-focal' status expresses perfective aspect in certain focus constructions. The Yucatec argument marking split fits with viewpointaspect-based splits in other languages - for example, Indo-Iranian languages such as Hindi - in that it associates an "ergative-absolutive" $(\mathrm{S}=\mathrm{U})$ pattern with perfective aspect and a "nominative-accusative" $(\mathrm{S}=\mathrm{A})$ pattern with non-perfective aspect. What makes it typologically rare is that the split occurs in intransitive rather than in transitive clauses (see Bohnemeyer 2004, Krämer \& Wunderlich 1999, and reference therein for discussion).

Table 2 lists the cells of the two cross-reference paradigms. The Set-B markers are suffixes; the Set-A markers clitics. They either procliticize to the head (in which case they end in the glides $y / w$ if the head starts with a vowel) or form a portmanteau with a preceding host; the second process appears to be restricted to a few fixed combinations.

\begin{tabular}{|l|l|l|l|}
\hline Number & Person & Set A & Set B \\
\hline \multirow{5}{*}{ SG } & 1 & $\operatorname{in}(w)=$ & -en \\
\cline { 2 - 4 } & 2 & $a(w)=$ & $-e c h$ \\
\cline { 2 - 4 } & 3 & $u(y)=$ & $-\varnothing(/-i h)^{2}$ \\
\hline \multirow{5}{*}{ PL } & 1 & $(a) k=\ldots\left(-o^{\prime} n\right)$ & $-o^{\prime} n$ \\
\cline { 2 - 4 } & 1 INCL & $(a) k=\ldots-o^{\prime} n e^{\prime} x$ & $-o^{\prime} n e ' x$ \\
\cline { 2 - 4 } & 2 & $a(w)=\ldots-e^{\prime} x$ & $-e^{\prime} x$ \\
\cline { 2 - 4 } & 3 & $u(y)=\ldots-o^{\prime} b$ & $-o^{\prime} b$ \\
\hline
\end{tabular}

Table 2: The morphological forms of the two paradigms of cross-reference markers

2 The 3SG ( $3^{\text {rd }}$-person singular) Set-B suffix is zero-marked across the Mayan language family. However, in Yucatec, the string /ih/ appears in this cell - and exclusively in this cell - on intransitive verbs of all classes, basic or derived (but exclusively on intransitive verbs). It is restricted to completive status and absolute clause-final position, i. e., when not followed by another morpheme or word belonging to the same clause. This string/ih/ can be analyzed as an innovated 3SG Set-B suffix that is restricted to clause-final position, intransitive verbs, and completive status. Alternatively, it can be treated as part of a completive status suffix the complete form of which varies across verb classes. The second analysis, however, requires a rule that deletes a particular segment of a 
As the table shows, the Set-B plural suffixes are also "grafted" onto Set-A-marked forms to express their plural cells. Even though these combinations do not appear to be compositional, the same strategy is also used to express the inclusive forms of the $1 \mathrm{PL}$ cell.

\subsection{Clause structure}

The Layered-Structure-of-the-Clause (LCS) theory of RRG states that, whereas verb phrases are language-specific constructions, clauses universally contain a so-called 'core', constituted in its turn by the expression of a semantic predicate the 'nucleus' - in combination with its syntactic arguments. A 'verbal core' is thus a kind of subject-internal verb phrase. In addition, each layer - the nucleus, the core, and the clause - has its own 'periphery', which accommodates modifiers specific to that layer. (More recent versions of RRG generalize LCS-like structures across lexical categories, postulating, in addition to verbal cores, nominal cores, adjectival cores, and so on.)

Nuclei, cores, and clauses can be complex, constituted by 'junctures' of units. There are three 'nexus' types that account for the relations between the units: subordination, whereby a unit is embedded as a an argument or modifier of another; coordination, whereby two otherwise independent units enter into a symmetrical combination; and cosubordination, a symmetrical combination between two nuclei, cores, or clauses that to some extent together behave like a single nucleus, core, or clause in that they have a shared operator projection and periphery and often also share arguments (cf. Van Valin 2005: 6-30, Bohnemeyer \& Van Valin ms., and Section 4).

Examples (3)-(4) above illustrate the contrast between verbal projections that carry a preverbal aspect marker, such as perfective $h$-in déekeh $h$-lúub-ech 'that you fell' in (4), and those that lack such a marker, such as the corresponding projection of lúub 'fall' in (3). We treat the presence of the preverbal aspect marker as expressing finiteness, following Bohnemeyer (2009b). It is no accident that the finite projection in (4) occurs with a (syntactically optional) complementizer, whereas the non-finite one in (3) does not and in fact excludes it.

particular morpheme - and only this segment of this morpheme - in a certain position. These two analyses seem to be about equally problematic. 
We assume that (4) instantiates clausal subordination, whereas (3) is a core cosubordination. Verbal cores constitute (matrix or subordinate) clauses by combining with exactly one member of a paradigm of 15 preverbal markers that express notions of viewpoint aspect, modality, and temporal 'remoteness' or distance from a reference time. Bohnemeyer (1998) coined the somewhat misleading term 'aspect-mood marker' for this preverbal slot. The term is misleading because mood, as opposed to modality, is not actually expressed in this position, but exclusively by the status suffixes on the verb. However, the preverbal marker in fact determines the status category the verb is inflected for. By hypothesis, the reason why no expressions of deictic or anaphoric tense - other than those 'remoteness' or 'metrical tense' markers - appear in the preverbal slot, even though this position appears to be tied to finiteness, is that Yucatec is a tenseless language (Bohnemeyer 1998, 2002, 2009a). In the matrix clauses of (2)-(6), the preverbal aspect-mood slot is filled by the perfective aspect marker $t$-. In the complement clause in (4), it is filled by the allomorph $h$ - of the same marker, which is restricted to intransitive verbs. The examples in (7) below feature the remote future marker biin in the preverbal slot.

Stative predicates such as those in (1), however, neither inflect for status nor do they combine with the preverbal aspect-mood markers. Moreover, they do not occur in embedded verbal cores. This is illustrated by the examples in (5). The desiderative matrix predicate subcategorizes for a core juncture. The second core cannot be projected by the nominal predicates $x c h$ 'úupo'b 'they are women' and $x i b o$ ' $b$ 'they are men' unless inchoative verbs are first derived from these nouns, as in $(5 b){ }^{3}$

$$
\begin{aligned}
& \text { *Bíin } u=t \text { s'íib+óol-t } x \text {-ch'úup-o'b xib-o'b, } \\
& \text { REM.FUT A3=write+soul-APP(B3SG) F-female-B3PL male-PL } \\
& \text { *bíin } u=t \text { 'śib+óol-t } t \quad x i b \text {-o'b } x \text {-ch'úup-o'b. } \\
& \text { REM.FUT A3=write+soul-APP(B3SG) male-B3PL F-female-PL }
\end{aligned}
$$

Intended: 'The men shall wish to be women, the women shall wish to be men.'

3 Note that the Set-A marker of the embedded cores in (5b) is omitted due to control by the matrix predicate. See Bohnemeyer (2009a) for a sketch of the grammar of control constructions in Yucatec. 
b. Bín u=ts'iib+óol-t x-ch'úup-tal xib-o'b, REM.FUT A3=write+soul-APP(B3SG) F-female-PROC.INC male-PL bíin $u=t$ 's'ib+óol-t xib-tal $x$-ch'úup-o'b. REM.FUT A3=write+soul-APP(B3SG) male-PROC.INC F-female-PL

'The men shall wish to become women, the women shall wish to become men.' (Vapnarsky 1995: 89)

The same holds for all types of stative predicates: the propositions 'I want to be tall/dead' cannot be expressed in a single sentence in Yucatec; only 'I want to become tall/dead' can.

With the exception of the morphologically bound perfective and imperfective markers (the former of which is illustrated in (2)-(4)), the preverbal aspect-mood markers can be shown to constitute stative predicates themselves. Thus, the mutually exclusive distribution of verbal cores and stative predicates partially explains why projections that carry preverbal aspect-mood markers are clauses rather than verbal cores. This generalization however in fact extends to projections formed with the morphologically bound perfective and imperfective markers as well - these too never occur in environments such as in (3) and (5), and we thus treat them as clauses rather than as verbal cores. Clauses can be embedded as relative clauses, but arguably not as complements in Yucatec. Finite complements such as that in (4) are, at least by hypothesis, adjoined rather than embedded. ${ }^{5}$

The morphological and distributional differences between clauses and verbal cores are important to the argumentation we present in Section 4, where we attempt to show that cross-referenced RPs can be core constituents in Yucatec.

4 This is a prophecy attributed by the narrator to spiritual leaders of the Cruzo'b Maya in the $19^{\text {th }}$ century. The term Cruzo'b was coined by Villa Rojas (1945) to designate a religious-military movement in the center of what is now the Mexican state of Quintana Roo, which erected an indigenous theocratic state in the midst of a guerilla war against the Mexican army in the second half of the $19^{\text {th }}$ century.

5 That clauses can in fact be embedded in Yucatec is assumed without argument in Norcliffe (2009). The main argument against this view comes from the observation that, whenever the expression of a proposition or state of affairs cross-referenced on a Yucatec predicate is 'finite', i. e., has its own preverbal aspect-mood marker, and thus has the structural properties of a Yucatec clause, it is always possible to have a member of the paradigm of clause-final indexical particles (mentioned below) intervening between the predicate and the clause. Since these particles mark the left edge of their clause, this suggests that the second clause is not a constituent of the first. In contrast, these particles do not intervene in core junctures. Cf. Bohnemeyer (2002: 90-98). 
The examples (1)-(4) illustrate two further properties that are of some consequence in the following. First, Yucatec is a verb-initial language, a trait shared throughout the Mayan language family. In transitive clauses with two clausemate cross-referenced RPs, both follow the verb, with the RP referring to the actor in final position, as illustrated in (6a):

(6) a. T-u=nes-ah

hun-túul pàal

PRV-A3=gnaw-CMP(B3SG) one-CL.AN child

$l e=x o h=o$,

$\mathrm{DEF}=$ cockroach $=\mathrm{D} 2$

'The cockroach bit a child' [elicited]

b. $T-u=n e s-a h$

PRV-A3=gnaw-CMP(B3SG)

'It bit it' [constructed]

Example (6b) illustrates the optionality of the RPs. In spontaneous connected discourse, clauses with multiple RPs are dispreferred (Skopeteas \& Verhoeven 2009). Instead, the RP with the most topical referent tends to be left-dislocated, as in (7):

(7)

$t$-u=nes-ah hun-túul pàal

$\mathrm{DEF}=$ cockroach=D2 PRV-A3=gnaw-CMP(B3SG) one-CL.AN child 'The cockroach, it bit a child'

For topical agent referents, this pattern is so pervasive that it has led some authors to analyze AVU (or Subject-Verb-Object, depending on the syntactic framework) as the basic constituent order in Yucatec clauses (Durbin and Ojeda 1978, Gutiérrez Bravo \& Monforte y Madera 2008, ms.). However, a variety of sources of evidence point to the conclusion that the initial RP in (7) is in fact left-dislocated (cf. Bohnemeyer 2009a, Skopeteas \& Verhoeven 2009):

- The position in question hosts the clitic indexical particles $=a^{\prime}$ (D1), $=o^{\prime}$ (D2, illustrated in (7)), and $=e^{\prime}(\mathrm{D} 3 / \mathrm{TOP})$ on its left edge. These particles do not occur clause-internally.

- The position is also routinely separated from the rest of the clause by an intonation break. 
- Expressions that occur in this position are not restricted to RPs and not necessarily cross-referenced on the verb. They may instead be adverbials designating the time or place about which the following clause makes an assertion or asks a question, etc., or RPs that stand in a variety of semantic relations to the arguments of the clause.

- The preference for a sentence-initial RP does not extend to intransitive clauses.

- The position in question does not admit non-topical elements. For instance, indefinite RPs only occur in this position in generic sentences and in sentences that do not contain a definite RP (e.g., in the very first sentence of a story).

We tentatively conclude that the position in question is the type of position identified in more recent versions of RRG (starting with Van Valin 1993) as the LeftDetached Position (LDP).

\subsection{Configurationality}

A question that has attracted considerable attention in the literature on crossreference marking is that of its relation to polysynthesis and configurationality. Jelinek's (1984) Pronominal Argument Hypothesis entails a direct causal link between cross-reference marking and non-configurationality: the non-configurational properties of languages such as Warlpiri - in particular, the syntactic optionality of RPs; their pragmatically determined position in linear order; their potential discontinuity; the occurrence of ergative argument marking splits between RPs and pronouns; and the absence of a VP node - are treated as a direct consequence of the adjoined syntactic status of RPs. Building on Jelinek's proposal, Baker (1991, 1996) argues that cross-reference marking, along with noun incorporation, is a hallmark of polysynthesis. However, Simpson (1991) and Austin \& Bresnan (1996), building on Hale (1983), present evidence from Warlpiri and other Australian languages that casts doubt both on the detached position of cross-referenced RPs (see Section 3) and on the typological co-distribution of the relevant properties. These authors argue that a framework such as Lexical Functional Grammar (LFG), which treats constituent structure, argument structure, and functional structure - the latter encoding grammatical relations and functional relations in terms of feature structures - as independent of one another, affords a superior treatment of cross-reference marking. RRG, the theory we as- 
sume for the purposes of this chapter, likewise offers treatments of constituency and functional categories in terms of independent representations. Syntactic aspects of argument structure are treated in RRG as encoded in the LSC, which does not map isomorphically into a traditional immediate-constituency representation, phrase structure grammar, or X-bar syntax. However, RRG parts company with LFG in that it treats grammatical relations as language-specific.

At first blush, Yucatec may appear to be a fairly configurational language. While RPs are syntactically optional (see (5)) and frequently appear in adjoined positions such as the LDP in (6), they are never discontinuous, ${ }^{6}$ and constituent order within the clause is relatively rigid (but see Skopeteas \& Verhoeven 2005). However, on closer inspection, the thematic relation a referent is assigned depends exclusively on the cross-reference marker that refers to it, not on the position of an RP in the clause. This can be seen from the fact that in a transitive clause with two $3^{\text {rd }}$-person arguments, the actor must outrank the undergoer on a topicality hierarchy if both arguments are to be realized by a combination of a cross-reference marker and a clause-internal RP. Aside from topicality, the ranking of the two argument referents is also sensitive to definiteness, humanness, and animacy. ${ }^{7}$ In (5) above, it is possible for a non-human actor to act on a human undergoer because the former is definite while the latter is indefinite. If this distribution is reversed, as in (8a), the intended interpretation can no longer be obtained. Native speakers confronted with such examples tend to express puzzlement and hilarity, explaining that the sentence can only mean that the child bit the spider. However, (8a) is not how the proposition 'The child bit a tarantula' would be expressed in spontaneous discourse - $(8 b)$ would be used for that instead.

${ }^{6} \mathrm{RP}$ constituents may trigger the selection of a clause-final indexical particle. For example, the definite article $l e$ in (8)-(9) triggers the distal/anaphoric particle $=o$ ' in clause-final position. The combination of the article and the particle serves as the Yucatec equivalent of a distal/anaphoric demonstrative. To express the meaning conveyed by the proximal demonstrative this in English, le combines with the clause-final particle $=a$ ' instead. However, triggering of the clause-final particles is not restricted to RP constituents. Triggers also include certain adverbs, preverbal aspect-mood markers, and negation. And irrespective of the position of the trigger, the particles occur exclusively on the right edge of the core clause and on that of the LDP. Hence, an analysis of these particles as discontinuous RP constituents is not parsimonious.

7 In addition, a clause-internal RP referring to the actor of the clause cannot be possessed by a clauseinternal RP referring to the undergoer. The agent-focus construction in (10) below was elicited as a consultant's repair of a stimulus utterance that was in violation of this constraint. A similar constraint has been described for other Mayan languages (e. g., Aissen 1999 for Tsotsil). 
(8) a. ??T-u=chi'-ah le=pàal hun-túul $x$-chìiwol=o'

PRV-A3=mouth-CMP(B3SG) DEF=child one-CL.AN F=tarantula=D2

'The child bit a tarantula'

\#'A tarantula bit the child'

b. T-u=chi'-ah hun-túul x-chìiwol le=pàal=o'

PRV-A3=mouth-CMP(B3SG) one-CL.AN F=tarantula DEF=child=D2

'The child bit a tarantula'

Meanwhile, the proposition 'A tarantula bit the child' simply cannot be expressed in an active transitive clause. Under predicate or sentence focus, either the actor $\mathrm{RP}$ is left-dislocated, as in (9a), or the verb is passivized, as in (9b).

(9) a. Hun-túul $x$-chiìwol=e,

one-CL.AN F-tarantula=TOP

$t-u=$ chi' $-a h \quad l e=p a ̀ a l=o^{\prime}$

PRV-A3=mouth-CMP(B3SG) DEF=child=D2

'A tarantula, it bit the child'

b. $H$-chi'-b le=pàal

PRV-mouth-PASS.CMP(B3SG) DEF=child

tumèen hun-túul $x$-chìiwol=o'

CAUSE one-CL.AN F-tarantula=D2

'The child was bitten by a tarantula'

A third option is the so-called 'agent focus construction' (Norcliffe 2009 and references therein). This construction is illustrated in (10). It involves an RP coreferential with the actor argument of the transitive verb in a focus position, which occurs between the LDP and the verb, ${ }^{8}$ deletion of the Set-A marker, special and defective aspect-mood and status paradigms, and, with habitual, generic, and future time reference, a special irrealis subordinator (cf. Bohnemeyer 2002: 116-129).

8 It has been a matter of some controversy whether this focus position is clause-internal - in which case it would likely instantiate the 'pre-core slot' position distinguished in Van Valin $(1993,2005)$ and Van Valin \& LaPolla (1997) - or whether all Yucatec focus constructions are biclausal, a kind of clefts in the broadest possible sense. The former position has been taken by Lehmann (2003), Gutiérrez Bravo \& Monforte (2009), and Skopeteas \& Verhoeven (2009, ms.), whereas the latter is advocated in Bricker (1979), Bohnemeyer (2002), Tonhauser (2003, 2007, ms.), and most recently in Vapnarsky (2013). 
Head-Marking and Agreement: Evidence from Yucatec Maya

(10) Pedro=e' uy=atan p'at-eh

Pedro=TOP A3=wife(B3SG) abandon-SUBJ(B3SG)

'Pedro, his wife (was the one who) left him'

Bohnemeyer (2009a) argues that the obviation/alignment constraints serve to regulate the coindexing between cross-reference markers and RPs. This suggests that, whether or not the Yucatec clause is considered configurational, its syntactic arguments are not realized by RPs alone. In the presence of cross-referenced RPs, the syntactic arguments of the clause might be the cross-reference markers alone or the combination of cross-reference markers and RPs, depending on the nature of the relation between cross-reference markers and cross-referenced RPs. This relation is the proper topic of this chapter. In the absence of cross-referenced RPs, the cross-reference markers are sufficient to realize the arguments.

In line with the set of facts just delineated, there is no evidence of a (subjectexternal) verb phrase node in Yucatec syntax. There are, for example, no VP anaphora (as in Sally wrote a paper on head-marking, and so did Floyd), VP ellipsis (as in Sally is writing a paper on head-marking and Floyd is too), or VP fronting constructions (as in What Sally did was write/writing a paper on head-marking) in this language. The following examples illustrate predicate focus constructions, the closest Yucatec equivalent to VP fronting. It is not possible for a focalized verb in this construction to retain an undergoer argument. In both instances, the focalized root-transitive verb is detransitivized, in (11) through antipassivization and in (12) through noun incorporation. ${ }^{9}$
Hàats' $\quad t$-in=mèet $-a h$
ti’ hit.
beat $\backslash$ ATP PRV-A1SG=make-CMP(B3SG) PREP hit
'Batting was what I did (lit. hitting was what I did to hits).'
(12) Hats'(-ah)+hit $k$-in=mèet-ik
beat(-ATP)+hit IMPF-A1SG=make-INC(B3SG)
'Batting (lit. hit-hitting) is what I do.'

The only verbal projection of Yucatec that can be argued to dominate a U-argument, but no A-argument, is the agent-focus verb form illustrated in (10) above.

9 The concept of batting (baseball is a popular sport across the Mexican Yucatan) is expressed by the idiom hats' hit composed out of the Yucatec verb 'hit' and the performance object (Dowty 1979) hit borrowed from English. 
This, however, is an odd candidate for a traditional VP, since it is restricted to transitive verbs and involves a co-constituent that necessarily has narrow focus and special aspect-mood and status patterns distinct from those of verbs under predicate or sentence focus.

As for split argument marking, Yucatec does indeed exhibit such a system, as illustrated above. But the split is based on status (semantically, on mood and viewpoint aspect), not on a nominal-pronominal contrast. To summarize, Yucatec shows those traits of non-configurationality that are robustly associated with cross-reference marking (or head-marking in a narrow sense of the term; see Section 3): RPs are syntactically optional; their referents receive semantic roles via their coindexing with cross-reference markers, not via their linear position in the clause; and there is no evidence of a subject-external VP node. But the language lacks other proposed non-configurational features such as discontinuity of RPs and a nominal-pronominal argument marking split.

\section{Head-marking in Role and Reference Grammar}

In this section, we discuss basic properties of cross-reference or head-marking and their current treatment in RRG and elsewhere in the literature. Where appropriate, we illustrate the relevant properties cited in the literature with Yucatec examples, in the process extending the discussion of cross-reference marking in Yucatec started in the previous section.

Nichols (1986) introduces the term 'head-marking' with a broader meaning than that adopted in Van Valin (1985) and the subsequent RRG literature. In Nichols' usage, any head-dependent relation can be morphologically encoded on the dependent, the head, both, or neither, where 'encoded' covers any morphological reflex of the relation. Head-marking in this broad sense thus includes subjectverb agreement in English and the 'construct state' form of nouns that occur with dependents in Semitic languages. In contrast, Van Valin narrows the term to a rough equivalent of what Bloomfield (1933: 191-194) called 'cross-reference' and Milewski (1950) a 'concentric' construction: a head carrying one or more bound morphemes which refer to the individuals that fill the head's semantic argument positions and which in the absence of clause-mate coreferential noun phrases or 'reference phrases' (RPs) act as pronouns. Depending on the language and 
construction, such RPs may optionally co-occur with the cross-reference markers (see the Yucatec examples in Section 2).

The traditional view of cross-reference markers (Humboldt 1836: 531, Boas 1911: 30, Bloomfield 1933: 191-194, Milewski 1950: 174, Nichols 1986: 107) can be summarized as follows:

- The head in combination with the cross-reference markers alone, in the absence of cross-referenced RPs, is syntactically complete and semantically readily interpretable, expressing the application of a semantic predicate to anaphoric arguments represented by the cross-reference markers. Therefore, the cross-reference markers are the syntactic arguments of the head.

- If there are cross-referenced RPs, they and the cross-reference markers cannot both realize the arguments - at least not separately. Since both are traditionally assumed to be referring expressions, are coindexed, and cannot stand in an anaphoric relation if they are constituents of the same clause (cf., e. g., Principle B of Chomsky's (1981) Binding Theory), they are treated as standing in an appositive relation instead. However, as Lehmann (1985: 92) points out, it is difficult to understand this appositive relation in its ordinary syntactic sense, since that would require the cross-reference markers to form higher RPs in combination with the cross-referenced RPs.

Jelinek (1984) analyzes the cross-referenced RPs as adjoined to the clause in Warlpiri (Ngarrkic, Pama-Nyungang; Northern Territories, Australia) and the Coast Salish languages Lummi and Klallam of British Columbia (see Pensalfini 2004 for a recent adaption based on Minimalism and Distributed Morphology). Simpson (1991) and Austin \& Bresnan (1996) point out one important obstacle for this analysis: if the RPs are detached, they should be able to anaphorically bind the cross-reference markers. But if the cross-reference markers are morphologically bound pronouns even in the presence of cross-referenced RPs, then they should be strictly definite, in the sense that they should only be able to pick up previously introduced discourse referents. The cross-reference markers of Warlpiri and other pronominal argument languages, however, occur with both definite and indefinite cross-referenced RPs, and cross-reference markers are used in combination with indefinite RPs to introduce new discourse referents. The same is true in Yucatec, as illustrated in (6)-(8) above. 
Diesing \& Jelinek (1995) develop an account of the semantics of cross-reference markers that treats them as ordinary pronouns in isolation and in combination with definite cross-referenced RPs, but as denoting variables in combination with indefinite cross-referenced RPs. These variables become the argument predicated over by the coindexed RP and are subsequently bound by existential closure. As Austin \& Bresnan (1996) point out, the same range of interpretations can be obtained under an alternative 'PRO-drop'-style account of cross-reference marking such as that proposed by Bresnan \& Mchombo (1987) for the subject markers of the Bantu language Chicheŵa of Malawi, Zambia, and Mozambique. Chicheŵa verbs cross-reference both subjects and objects. The object cross-reference markers are optional and in complementary distribution with object RPs, whereas the subject markers are obligatory and co-occur with syntactically optional RPs. Bresnan \& Mchombo analyze the object markers as incorporated pronouns, the presence of which excludes that of a clause-mate cross-referenced RP. In the presence of an object marker, a cross-referenced RP, if present, is relegated to a detached ('topic') position adjoined at the sentence level. The authors term the relation between the object marker and the detached RP 'anaphoric agreement'. In contrast, they argue the subject markers to be ambiguous between anaphoric and grammatical agreement: in the absence of a clause-internal subject RP, they function as incorporated pronouns, like the object markers; but in the presence of a clause-internal subject RP, they express grammatical agreement. This is the same distribution shown by the verb agreement morphology of Romance languages and many languages of the Balkan sprachbund (e. g., Jaeger \& Gerassimova 2002 on Bulgarian). Perlmutter 1971 coined the term 'PRO-drop' for this phenomenon.

Van Valin (2013) points out two additional problems with applying Jelinek's analysis cross-linguistically: in Lakhota (Siouan; Great Planes), detached material tends to be separated from the matrix clause by intonation breaks, whereas RPs inside the intonation contour of the main clause are perfectly inconspicuous. The same is true in Yucatec: whereas the left-dislocated RPs on the left edge of the sentence in (7), (9a), and (10) above are separated from the following material by both a pause and a discontinuity in the pitch contour, neither property applies to the post-verbal RPs in (5)-(9). ${ }^{10}$

\footnotetext{
${ }^{10}$ The focus position in (10) is likewise intonationally integrated with the following material. There is also a 'right-detached position' expressing an 'anti-topic' in the sense of Lambrecht (1994) on the right edge of the sentence that is intonationally isolated from the rest.
} 
Moreover, detached material is not expected to appear in embedded clauses, and cross-referenced RPs do occur in this environment in Lakhota. This argument likewise applies to Yucatec as well, as the relative clauses in (13)-(14) illustrate:

$$
\begin{aligned}
& \text { K'àas le=máak } \\
& \operatorname{bad}(\mathrm{B} 3 \mathrm{SG}) \mathrm{DEF}=\text { person } \\
& {\left[t-a=t s^{\prime} a^{\prime}-a h \quad l e=t a^{\prime} k i n \quad t i^{\prime}\right]=o^{\prime}} \\
& \text { PRV-A2=put-CMP(B3SG) DEF=money PREP(B3SG)=D2 }
\end{aligned}
$$

'The person you gave the money to is bad'

(14) Káa $=h$-òok

$\mathrm{CON}=\mathrm{PRV}$-enter(B3SG)

le $=x$-ch'úup $\quad[$ chak $\quad u=n o ̀ o k ']=o ',(.$.

$\mathrm{DEF}=\mathrm{F}-$ female $\operatorname{red}(\mathrm{B} 3 \mathrm{SG}) \mathrm{A} 3=$ garment=D2

'And (then) the woman in the red dress (lit. the woman her dress is red) entered, (...)'

Since the relative clauses occur on the right edge of the matrix clause, it might be argued that they are themselves adjoined to the clause. However, the placement of the clause-final deictic particle excludes this possible analysis in (14), as this particle is triggered by the definite article of the RP modified by the relative clause. Nor can this entire higher RP be detached in (14) - if it were, the verb would carry the suffix $-i h$, which can be analyzed as either an allomorph of the - normally zero-marked - 3SG Set-B cross-reference marker or a segment of a completive status marker (see footnote 2).

Van Valin (1985) develops an analysis of the cross-referenced RPs as clauseinternal adjuncts in the early version of the LCS model of RRG proposed in Foley \& Van Valin (1984). ${ }^{11}$ This early model assumes a single periphery, which in combination with the core constitutes a clause. A key assumption of the RRG analysis - then and now - is that the cross-reference markers, and not the crossreferenced RPs, are the true syntactic arguments of the head. This entails that the cross-referenced RPs cannot be core constituents, since the core is constituted by definition by the predicate nucleus and its syntactic arguments. Van Valin (1985) concludes that the cross-referenced RPs, when occurring clause-internally, must occupy the (clausal) periphery, much like adjuncts.

${ }^{11}$ Although published later, Van Valin's account predates Jelinek's, being a restatement of Van Valin (1977) in the framework first sketched in Van Valin \& Foley (1980). 
This adjunct analysis faces several complications, as discussed in Van Valin (2013). Unlike true adjuncts in Lakhota, cross-referenced RPs may not be headed by adpositions. And true adjuncts in turn are not cross-referenced on the verb, nor does the verb subcategorize for them. Both of these problems are in fact addressed in Van Valin (1985): The cross-referenced RPs are analyzed as 'referencerestricting modifiers' of the cross-reference markers. This would explain why they do not behave like adjuncts. And the subcategorization facts are explained with reference to a 'Coherence Condition' (Van Valin 1985: 380) adopted from Bresnan (1982) and an additional 'Agreement Condition', which requires the RPs to be semantically compatible with the cross-reference markers in the relevant semantic features person, number, and animacy, following up on the idea that it is the cross-referenced RPs that agree with the head, rather than the other way around, first proposed in Van Valin (1977).

However, while it is thus in fact possible to solve the problems resulting from the adjunct analysis, the proposed solutions remain somewhat stipulative. The fundamental fact remains that cross-referenced RPs are not adjuncts and thus do not really belong in the periphery. In search of alternatives, Van Valin (2013) explores the syntactic positions newly added to the model in Van Valin (1993) and the subsequent literature (e.g., Shimojo 1995): in particular, the left- (LDP) and right-detached positions (RDP) and the pre-core (PrCS) and post-core slot (PoCS). As already mentioned, the LDP and RDP cannot account for the properties of the post-verbal RPs in (5)-(9), since the former, but not the latter, are separated from the verb and the main clause by intonation breaks and the placement of the clause-final clitic particles. Moreover, as illustrated above, cross-referenced RPs are freely permissible in subordinate clauses, which the LDP and RDP are not. This second source of evidence also discourages an association with the PrCS and PoCS, both of which express marked information perspectives, in particular (though not restricted to) focus.

Van Valin (2013) therefore proposes a new type of position to accommodate the cross-referenced RPs in Lakhota and other head-marking languages: the 'extracore slot' (ECS). Like the PrCS and PoCS, ECSs are immediate daughters of the clause. However, they differ from the PrCS and PoCS in the following properties:

- $\quad$ ECSs are not associated with marked information perspective.

- ECSs are licensed by the cross-reference markers on the nucleus. Therefore, ECSs occur exclusively in head-marking constructions, are restricted to 
cross-referenced RPs (whereas the PrCS and PoCS can accommodate other syntactic categories), and a clause has exactly as many ECSs as its nucleus or nuclei carry cross-reference markers (whereas every clause has exactly one PrCS and PoCS).

In the next section, we present evidence discouraging the analysis of the crossreferenced RPs as immediately dominated by the clause in Yucatec. This is followed by a section reviewing evidence from two production experiments on plural marking in Yucatec. The results of these studies are best explained assuming that, in the presence of a cross-referenced RP, the number component of the crossreference marker does in fact express agreement with the RP. Together, these facts encourage a PRO-drop-style analysis of the Yucatec cross-reference markers following the model of Bresnan \& Mchombo's analysis of the subject markers of Chicheŵ.

\section{The case for core-internal RPs}

Core cosubordinations are constituted by two cores forming a superordinate core through sharing an operator projection and periphery and typically (possibly necessarily; cf. Bohnemeyer \& Van Valin ms.) also an argument in a control(or 'equi-NP-deletion') or matrix-coding-like (i.e., 'raising'-like) structure. An example is the event perception construction in (3) above, repeated in (15) for convenience:

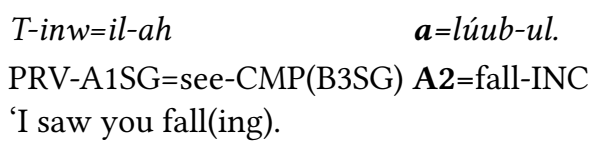

The crucial property of Yucatec core cosubordinations for our purposes is the ability for an RP cross-referenced on the nucleus of the first core to be realized between the two verbs, as illustrated in (19)-(21) below. The first author tested these examples with six native speakers, all of whom accepted all of them. The examples instantiate event perception (17), causative light verb (18), and 'motioncum-purpose ${ }^{12}$ (19) constructions.

12 Motion-cum-purpose constructions combine a 'path' verb (Talmy 2000) with a second verbal projection that describes an eventuality intended and/or expected to occur at the goal of the path (cf. 
How do we know that these constructions are core cosubordinations? Before we attempt to answer this question, let us introduce a terminological convention. Non-RRG syntacticians might call the first verbal projection in these examples the 'matrix' and the second 'embedded'. However, RRG distinguishes three different 'nexus' relations between verbs (or, more generally, nuclei) or their projections (or, more generally, the projections of nuclei) - subordination, coordination, and cosubordination. Only one of these - subordination - is defined as involving embedding of one nucleus, core, or clause into another in an argument or adjunct position. At first blush, one might think that that is exactly what is going on in (19)-(21): in all cases, the first verb semantically opens up an argument position filled by the projection of the second verb. However, on closer inspection, this second projection turns out not to be a syntactic argument of the first verb in any of the examples. The first verb is in all cases a transitive verb with a human actor argument. If the second projection were the undergoer argument of these transitive verbs, it ought to be possible to passivize the verb and turn the second projection into the S-argument of the passivized verb. This is, however, not possible in any of these cases. We will therefore use the terms 'licensing' verb/core for the first verb and the core it projects, respectively, and 'licensed' verb/core for the second verb and its core (cf. also Bohnemeyer \& Van Valin ms.).

The second verbal projection in these examples is quite clearly a core, given the absence of the preverbal aspect-mood marker (cf. Section 2). Assuming subordinative nexus is out of the question and the other two nexus types, coordination and cosubordination, are symmetrical (nucleus-nucleus, core-core, clause-clause), this leaves us with two competing analyses: core coordination and core cosubordination. Definitionally, these are distinguished by the two cores in the latter, but not the former, forming a single superordinate constituent with all the trappings of a core in the LSC - that is, by sharing an operator projection and a periphery. Argument sharing - control and matrix coding (or 'raising') - occurs with both coordinative and cosubordinative nexus, although by hypothesis, the latter, but not the former, necessarily involves argument sharing (and most commonly apparently control; cf. Bohnemeyer \& Van Valin ms.). There is a variety of diagnostics for periphery sharing. One of them is the ability to have separate temporal modifiers in the two cores: a shared periphery excludes this ability. Ex-

Aissen 1987 for Tsotsil and Zavala Maldonado 1993 for an overview including other members of the Mayan language family). 
clusion of distinct temporal modifiers is illustrated in (16) for the event perception construction, in (17) for the causative light verb construction, and in (18) for the motion-cum-purpose construction. In each case, it is acceptable to use a single time adverbial denoting an interval in which both sub-events fall. ${ }^{13}$

(16) Las sèeyse', $t$-inw=il-ah

six.o'clock PRV-A1SG=see-CMP(B3SG)

u=hàan-t $-i k \quad l e=b a k$ ' le=pèek' (\#las syèeteh $)=o$ '.

A3=eat-APP-INC(B3SG) DEF=bone DEF=dog seven.o'clock=D2

'At six, I saw the dog eat(ing) the bone (\#at seven).'

(17) Juanita $=e^{\prime} \quad$ byèernes- $a k=e^{\prime} \quad t$ - $u=$ mèet $-a h$

Juanita=TOP Friday-CAL=TOP PRFV-A3=make-CMP(B3SG)

$u=$ mìs- $t$ - $i k \quad u=n a h-i l \quad$ Pedro (\#sàabado)

A3=broom-APP-INC(B3SG) A3=house-REL Pedro Saturday

'Juanita, last Friday, she made Pedro sweep her/his house (\#on Saturday)'

(18) Fuanita $=e^{\prime} \quad$ byèernes- $a k=e^{\prime} \quad h$-bin

Juanita=TOP Friday-CAL=TOP PRV-go(B3SG)

uy $=$ Pedro (\#sàabado)

A3=see(B3SG) Pedro Saturday

'Juanita, last Friday, she went to see Pedro (\#on Saturday)'

Contemporaneity is a necessary feature of event perception (called 'direct perception' in the RRG literature), so all the inadmissibility of adverbials denoting non-overlapping time intervals in (16) tells us is that we are indeed dealing with event perception. The causative and motion-cum-purpose examples in (17) and (18) are more revealing in this respect, as there is no obvious semantic factor excluding distinct time adverbials here. ${ }^{14}$

${ }^{13}$ Lorena Pool Balam (p.c.) points out that, whereas (16) is uninterpretable, (17)-(18) sound merely awkward. However, a group of seven speakers tested by the first author in 2002 rejected (17).

${ }^{14}$ We include the event perception example in (16) because the event perception construction, like the other two construction types, allows core-medial RPs. And it should go without saying that just because the semantics of this construction severely limits the possibility for temporal modification does not mean that it should not be treated as a core cosubordination. After all, it is the semantic properties of the complex events described by a particular nexus type that condition the use of that nexus type. 
Under the assumption of cosubordinative nexus, the possible positioning of an RP cross-referenced on the licensing verb between the two verbs is at odds with the assumption that the cross-referenced RPs are immediate daughters of the clause. In (19a), the RP le pèek' 'the dog' refers to the undergoer of the perception verb and to the actor of the ingestion verb. These two semantic arguments are 'shared' in a control (i. e., 'equi') construction. Control is realized in Yucatec by cross-referencing both the controller and the target argument (put differently, by cross-referencing the controlled argument on both the 'licensing' and the 'licensed' nucleus), but allowing at most one cross-referenced RP (cf. Bohnemeyer 2009a). In (19a), this RP appears between the two verbs. Given general properties of Yucatec clause structure (see Section 2), this RP cannot be a constituent of the second core or even adjoined to the second core. It can, however, be a constituent of the first core or be adjoined to it. But if the ECS is directly dominated by the clause, the superordinate core formed by the two constituent cores would have to be discontinuous in order to accommodate the RP. Given the absence of discontinuous syntactic projections in Yucatec, this analysis lacks parsimony.

$$
\begin{aligned}
& \text { a. T-inw=il-ah le=pèek' } \\
& \mathrm{PRV}-\mathrm{A} 1 \mathrm{SG}=\text { see-CMP(B3SG) } \mathrm{DEF}=\mathrm{dog} \\
& u=h a ̀ a n-t-i k \quad l e=b a k^{\prime}=o \text { ' } \\
& \text { A3=eat-APP-INC(B3SG) DEF=bone=D2 } \\
& \text { 'I saw the dog eat(ing) the bone.' } \\
& \text { b. T-inw=il-ah u=hàan-t-ik } \\
& \text { PRV-A1SG=CMP(B3SG) A3=eat-APP-INC(B3SG) } \\
& l e=b a k{ }^{\prime} \quad l e=\text { pèek' }^{\prime}=o^{\prime} \\
& \mathrm{DEF}=\text { bone } \mathrm{DEF}=\mathrm{dog}=\mathrm{D} 2 \\
& \text { 'I saw the dog eat(ing) the bone.' }
\end{aligned}
$$

As (19b) illustrates, it is also possible for the cross-referenced RP to be realized after the second verb, and most speakers in fact prefer this position to the one in (19a). ${ }^{15}$ Intonation and the placement of clause-final deictic particles once again suggest that the position of the right-most RP in (19b) is not the RDP. We

\footnotetext{
${ }^{15}$ Note that the speakers were asked to rank the different realizations after they had already established that all of them were grammatical. Thus, the preference for the sentence-final realization in a forced-choice ranking task is interesting, but it is unclear what it reflects. The same point applies to the following examples, all of which produced similar rankings.
} 
assume that the right-most RP in (19b) is either a constituent of the higher core or adjoined to it. Meanwhile, the possibility of a cross-referenced RP to occur between the verbs in (19a) discourages the analysis of the cross-referenced RP as an immediate daughter of the clause.

The examples in (20) instantiate the causative light verb construction with mèet 'make'. The actor of the licensing verb is the causer, while the undergoer of the licensing verb controls the actor of the licensed verb, which is the causee. In (20a-b), both verbs are transitive active-voice forms. In (20a), the RP Pedro occurs between the two verbs and can be interpreted as referring to either the causer or the causee. Our consultant seemed to find both interpretations about equally salient. In contrast, in (20b), with Pedro in final position, this RP is apparently more likely to be understood to refer to the causee. In (20c), where the licensed core is passivized and Pedro is flagged by the oblique-actor preposition tuméen, it can of course refer exclusively to the causee. When asked to rank these examples, most consultants indicated a preference for (20c) over (20b) and for (20b) over (20a). Nonetheless, all judged (20a) to be wellformed, suggesting that Pedro is not immediately dominated by the clause. ${ }^{16}$
a. Le=òok'ol=o' $t$-u=mèet $-a h \quad$ Pedro
$\mathrm{DEF}=$ steal=D2 PRV-A3=make-CMP(B3SG) Pedro
$u=c^{\prime}{ }^{\prime}$ '-ik le $=$ ta' $^{\prime} \mathrm{kin}=\mathrm{o}^{\prime}$
A3=take-INC(B3SG) DEF=money=D2
'The thief, (s)he made Pedro take the money'
or 'The Thief, Pedro made him/her take the money'
b. Le=òok'ol=o' $t$-u=mèet- $a h \quad u=c h$ ' $a$ '-ik
$\mathrm{DEF}=$ steal=D2 PRV-A3=make-CMP(B3SG) A3=take-INC(B3SG)
le $=$ ta'kin Pedro $=o^{\prime}$
$\mathrm{DEF}=$ money Pedro=D2
'The thief, (s)he made Pedro take the money'
(or 'The Thief, Pedro made him/her take the money')

\footnotetext{
${ }^{16}$ An anonymous reviewer wonders whether the participants' preference for (20a) and (20b) over (20c) does not invalidate the analysis we are arguing for. However, the key fact here is that all consultants judged the structures with the medial RPs to be wellformed. That they also preferred the sentence-final strategy when asked to make a forced choice is interesting, but it is unclear what this ranking reflects.
} 
c. Le=òok'ol=o' $t$-u=mèet- $a h \quad u=c h$ ' $a$ '- $b$ - $a l$

$\mathrm{DEF}=$ steal=D2 PRV-A3=make-CMP(B3SG) A3=take-PASS-INC

le $=$ ta'kin tuméen Pedro=o'

$\mathrm{DEF}=$ money CAUSE Pedro=D2

'The thief, (s)he made Pedro take the money (lit. made the money be taken by Pedro)'

Lastly, in the motion-cum-purpose constructions in (21), the RP le pàal 'the child' refers to the undergoer of the licensing verb and the actor of the licensed verb. The two verbs again 'share' this argument via control. The alternative final realization of the RP is again possible as well. In this case, both orders are considered equally good.

$$
\begin{aligned}
& \text { Pablo=e' } \quad t-u=t u ́ u x t-a h \quad l e=p a ̀ a l \\
& \text { Pablo=TO PPRV-A3=send-CMP(B3SG) } \mathrm{DEF}=\text { child } \\
& u=c h ' a ' \quad l e=t a^{\prime} k i n=o ' \\
& \text { A3=take(SUBJ)(B3SG) } \mathrm{DEF}=\text { money=D2 }
\end{aligned}
$$

'Pablo, he sent the child to take the money'

b. Pablo=e' $t$-u=túuxt-ah $\quad u=c h^{\prime} a^{\prime}$

Pablo=TOP PRV-A3=send-CMP(B3SG) A3=take(SUBJ)(B3SG)

$l e=t a ' k i n \quad l e=p a ̀ a l=o$ '

$\mathrm{DEF}=$ money $\mathrm{DEF}=$ child $=\mathrm{D} 2$

'Pablo, he sent the child to take the money'

Given the absence of discontinuous syntactic projections in Yucatec, the crossreferenced $\mathrm{RP}$ on the right edge of the first core is unlikely to be immediately dominated by the clause in these examples, since it would be interrupting the higher core formed by the two cosubordinate cores, as illustrated in Figure 1 for (21a).

There are two conceivable alternative analyses of the cross-referenced RP that would be consistent with its position on the right edge of the first core. First, the cross-referenced RP might be adjoined to the first core. To our knowledge, the existence of core-layer adjunction has never been argued for before, but such an analysis would seem consistent with the observable facts. Or secondly, the cross-referenced RP is in fact a constituent of the first core. In this case, it has 


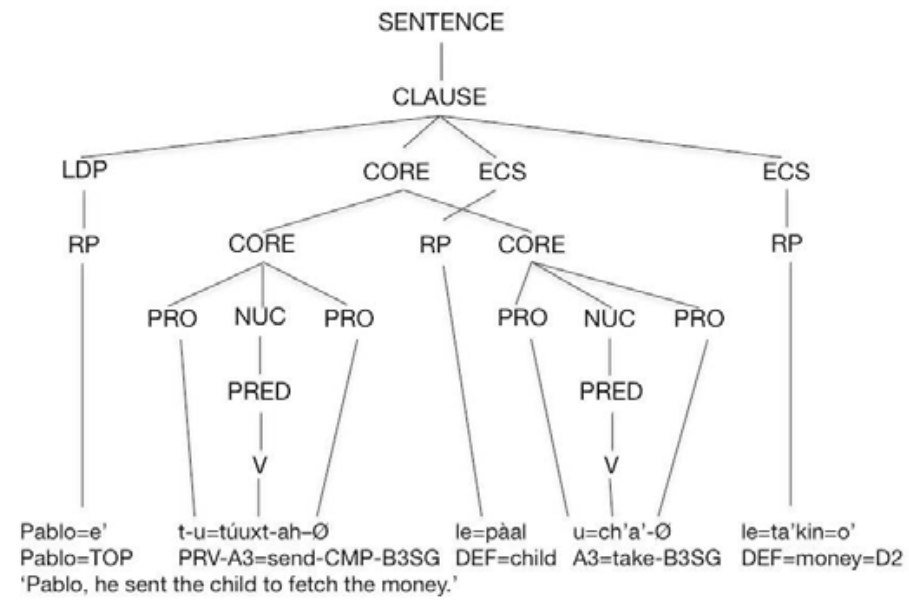

Figure 1: An analysis of (21a) in the style of Van Valin (2013)

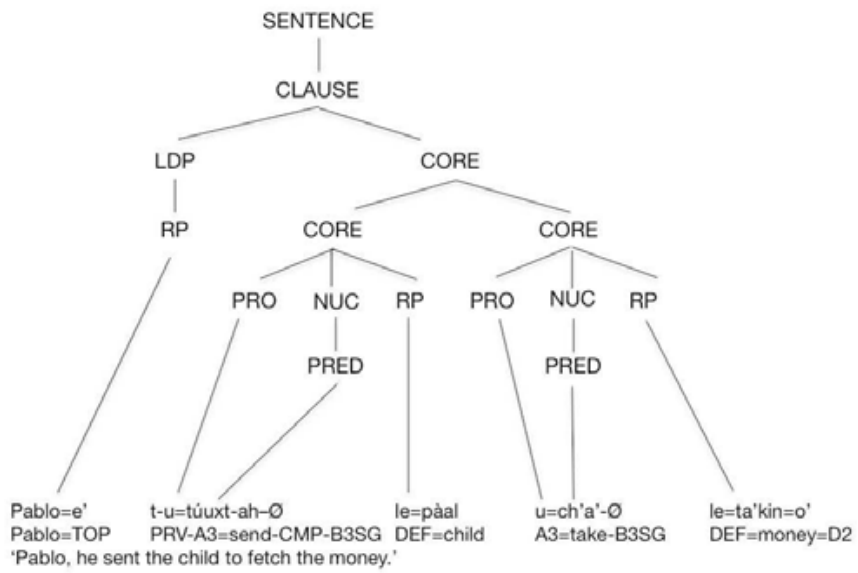

Figure 2: A pro-drop analysis of (21a)

to be an argument of the first verb by definition, which means the coindexed cross-reference marker can only express agreement, in line with an ambiguous, PRO-drop-style analysis along the lines of Bresnan \& Mchombo (1987). In the next section, we present evidence from two production experiments supporting the latter analysis. This analysis is represented in Figure 2. 


\section{The case for syntactic agreement}

\subsection{Introduction}

Both nouns and verbs inflect for number in Yucatec. On the verb, semantic plurality of an argument can be expressed by selection of the plural cells of the crossreference markers (cf. Table 2 in Section 2). RPs with nominal heads can express plurality of the referent through the noun suffix $-o^{\prime} b$, which is homophonous with the B3PL pronoun. The ambiguous analysis of cross-reference marking in Yucatec predicts that cross-referenced RPs and their coindexed cross-reference markers coincide in the inflectional category expressed on Yucatec nouns, which is number. Any core-external (i. e., non-argument) analysis of the cross-referenced RPs makes the same prediction in connection with the Agreement Condition of Van Valin (1985) (see Section 3). However, there is a difference, which results from the serendipitous fact that plural marking is optional on $3^{\text {rd }}$-person arguments in Yucatec, in the sense that the $3 \mathrm{SG}$ cells of the cross-reference paradigms (shown in Table 2 above) and RPs which lack the plural suffix are also compatible with plural interpretations, as illustrated in (22):

(22) a. Táan $u=k$ 'àay le $=x$-ch'úupal=o'

PROG A3=sing $\backslash$ ATP DEF=F-female:child=D2

'The girl(s) is/are singing'

b. Táan $u=k$ 'àay-o'b le=x-ch'úupal=o'

PROG A3=sing $\backslash$ ATP-3PL DEF=F-female:child=D2

'The girls are singing'

c. Táan $u=k^{\prime}$ àay $\quad l e=x$-ch'úupal-o'b=o'

PROG A3=sing $\backslash$ ATP DEF=F-female:child-PL $=$ D2

'The girls are singing'

d. Táan $u=k$ 'àay-o'b le=x-ch'úupal-o'b=o'

PROG A3=sing $\backslash A T P-3 P L$ DEF=F-female:child-PL=D2

'The girls are singing'

The unmarked forms in (22a) are compatible with both singular and plural interpretations - they are semantically transnumeral. In contrast, if the verb (22b), the RP (22c), or both (22d) are plural-marked, a plural interpretation is entailed (cf. Butler 2012, Butler et al. 2014). 
Crucially, the Agreement Condition of Van Valin (1985) merely requires crossreference markers and cross-referenced RPs to be semantically compatible in terms of the expressed features. This constraint is met in all four examples in (22). In contrast, under the ambiguous analysis, the cross-reference marker expresses syntactic agreement with the cross-referenced RP. We take this to mean that the same feature must be morphologically specified in both positions. This constraint is met in (22a) and (22d), but not in (22b)-(22c).

The fact that native speakers accept all four configurations in (22) as syntactically wellformed and consistent with the interpretations indicated by the translations represents prima facie evidence against the ambiguous analysis. However, very little is known about number agreement in languages with optional plural marking outside Wiltschko (2008) and Butler (2012). It is conceivable that the distribution of plural markers across nouns and verbs is less categorical in such a language. If so, corpus and production studies are what is called for to adjudicate between the two competing analyses.

In Butler et al. (2014), we reported two production experiments. During the first, Yucatec native speakers translated stimulus utterances from the contact language Spanish; during the second, they described stimulus pictures. In both cases, the stimuli featured various actions, some involving a single individual (the 'One' condition), some two individuals (the 'Two' condition), and some many (seven in the picture stimuli; the 'Many' condition).

The distinction between the Two and Many conditions is relevant because Yucatec has numeral classifiers. Yucatec numerals prefix to these classifiers. However, these autochthonous Yucatec numerals are used only for numbers in the subitizing range (up to three, sometimes four; cf. (23)). Higher numbers are expressed with Spanish loans, which do not combine with the classifiers, as in (24). Classifiers in turn are sometimes assumed to be in complementary distribution with respect to plural markers, because they are argued to overlap in their semantics (cf. Borer 2005 and references therein). Hence the contrast in (23)-(24):

(23) kan-túul máak four-CL.AN person 'four people'
(24) sìnko máak-o’b

five person-PL

'five people' (constructed) 
We thus included the Two condition specifically in the hopes that it might afford us a dissociation between plural reference and plural marking.

Next we provide a brief description of the methodology (for more detail, we refer to Butler et al. 2014).

\subsection{Method summary}

Table 3 exemplifies the stimuli we used for the translation task, along with some possible Yucatec responses. There were a total of 30 intransitive stimulus sentences and 32 fillers, consisting of transitive sentences and sentences with adjectival predicates.

\begin{tabular}{|l|l|l|}
\hline Cond. & Spanish stimulus & Possible Yucatec response \\
\hline One & $\begin{array}{l}\text { El muchacho está jugando } \\
\text { DEF boy be.at:3SG play:GER } \\
\text { 'The boy is playing' }\end{array}$ & $\begin{array}{l}\text { Táan u=bàaxal le=xibpal=o' } \\
\text { PROG A3=play DEF=male:child=D2 } \\
\text { 'The boy is playing' }\end{array}$ \\
\hline Two & $\begin{array}{l}\text { Dos muchachos están jugando } \\
\text { two boy:PL be.at:3PL play:GER } \\
\text { 'Two boys are playing' }\end{array}$ & $\begin{array}{l}\text { Táan u=bàaxal(-o'b) ka'-túul xibpal(-o'b) } \\
\text { PROG A3=play(-PL) two-CL.AN male:child(-PL) } \\
\text { 'Two boys are playing' }\end{array}$ \\
\hline Many & $\begin{array}{l}\text { Los muchachos están jugando } \\
\text { DEF.PL boy:PL be.at:3PL play.GER } \\
\text { 'The boys are playing' }\end{array}$ & $\begin{array}{l}\text { Táan u=bàaxal(-o'b) le=xibpal(-o'b)=o' } \\
\text { PROG A3=play(-PL) DEF=male:child(-PL)=D2 } \\
\text { 'The boys are playing' }\end{array}$ \\
\hline
\end{tabular}

Table 3: Some stimuli in the translation experiment and possible Yucatec responses

The stimuli were created with a speech synthesizer. Participants would listen to them over a headset and then record their responses. They would hear each sentence at least once, but had the option of listening to two repetitions.

Figure 3 shows some of the stimulus pictures we used for the picture description task. There were 24 items, all featuring single-participant actions, and 48 fillers showing two-participant actions, the latter varied in terms of the number of entities involved as undergoers. Participants would view the pictures on a computer screen and then record single-sentence responses.

The experiments were conducted by the second author at the Universidad del Oriente in Valladolid, Yucatan, Mexico. Thirty speakers (mostly college-aged) participated in the translation study and 37 speakers aged 19-26 in the picture description task. The participants were given oral instructions from the experimenter and written instructions on screen in Spanish and then completed four practice trials before the experimental trials began. 

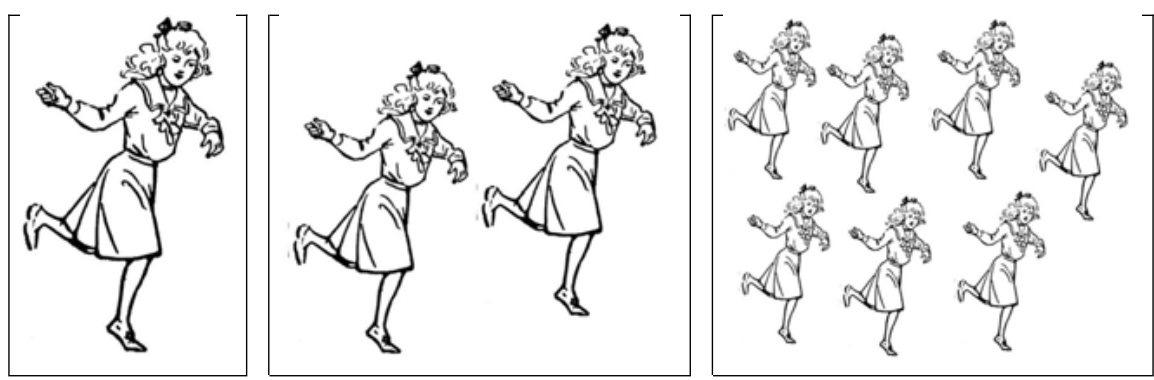

Figure 3: Examples of stimulus pictures in the One (left), Two (center), and Many (right) conditions

Responses were transcribed and coded by the second author with the assistance of two native speakers. Only intransitive Yucatec responses that represent the content of the stimuli items broadly correctly and feature a verb, an RP, and a numeral are included in the analyses presented below. Responses with Spanish words are included in case the words in question carry Yucatec morphology where appropriate. These criteria netted 704 of the 900 critical responses to the translation task $(78.2 \%)$ and 556 out of 648 critical responses to the picture description task $(86 \%)$ for inclusion in the analysis.

\subsection{Result summary}

The graphs in Figures 4 shows the proportion of plural marking on the noun only, on the verb only, on both, and on neither for the two tasks.
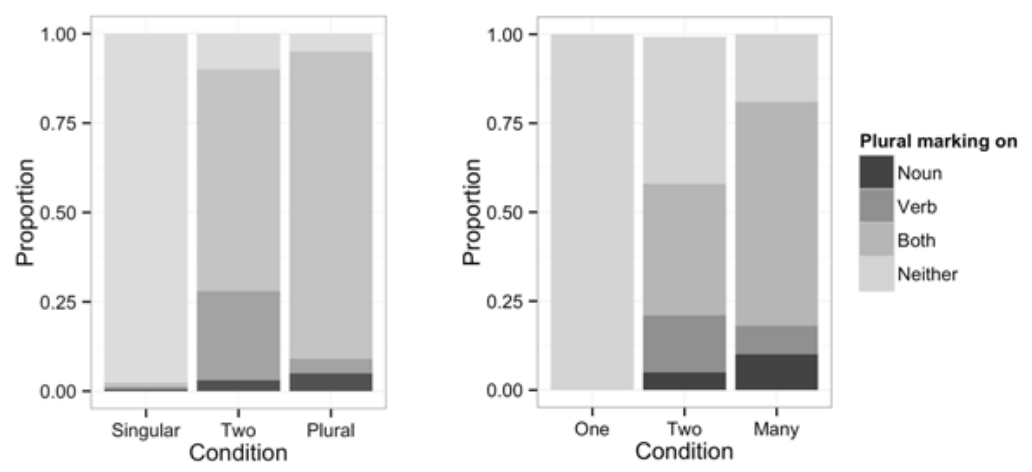

Figure 4: Proportion of plural marking on the noun, verb, both, and neither by condition (left: translation task; right: picture description task) 
The results confirm, first of all, that plural marking is indeed optional in Yucatec, as a sizeable percentage of responses to the picture description task in the semantically plural Two and Many conditions did not feature any plural marking.

The difference between the two tasks is significant and likely the result of crosslinguistic priming, which we do not discuss further here (but see Butler et al. 2014). Despite the overall difference in the rate of plural marking between the two experiments, participants in both experiments exhibited qualitatively similar (though not identical) patterns of plural marking for the three conditions.

As predicted, the rate of nominal plural marking in the Two condition fell between those in the One and Many conditions. Nominal plural marking was more frequent in the Two condition than in the One condition (translation: $\chi^{2}(1)=$ 212.6, $\mathrm{p}<.0001$; picture description: $\left.\chi^{2}(1)=101.5, \mathrm{p}<.0001\right)$, but less frequent than in the Many condition (translation: $\chi^{2}(1)=44.1, \mathrm{p}<.0001$; picture description: $\left.\chi^{2}(1)=33.5, \mathrm{p}<.0001\right)$. Verbal plural marking was likewise more frequent in the Two than in the One condition (translation: $\chi^{2}(1)=340.0, \mathrm{p}<.0001$; picture description: $\left.\chi^{2}(1)=139.7, \mathrm{p}<.0001\right)$. However, a significant difference in verbal plural marking between the Two and Many conditions emerged only in the picture description experiment (translation: $\chi^{2}(1)=1.0, p>.3$; picture description: $\left.\chi^{2}(1)=11.0, \mathrm{p}<.0001\right)$.

Crucially for present purposes, participants in both experiments preferred to mark plural on either both the noun and the verb or neither (translation: Spearman rank $\mathrm{R}^{2}=0.58, \mathrm{p}<.0001$; picture description: $\mathrm{R}^{2}=.54, \mathrm{p}<.0001$ ). This finding is in line with the predictions of the PRO-drop/agreement hypothesis. In contrast, under the core-external analysis of the cross-referenced RPs, plural marking on both nouns and verbs is redundant and thus might be expected to be dispreferred on pragmatic grounds.

At the same time, the existence of a sizable proportion of responses that featured plural marking on either the verb or the noun, but not both, indicates that if there is indeed an effect of morphosyntactic agreement in our data, it is at the very least not of a categorical nature. But this is to some extent the case even in bona fide cases of syntactic agreement, such as subject-verb agreement in English, where agreement errors are reported to occur in a frequency range not too far off from what the frequency of mismatches we found produced by Yucatec speakers (e. g., Bock \& Eberhard 1993, Bock \& Miller 1991, Hartsuiker, Schriefers, Bock \& Kikstra 2003, Vigliocco, Butterworth \& Semenza 1995). 
Conspicuously, verbal plural marking unaccompanied by nominal plural marking was more common than the inverse: out of 362 responses to the translation task that featured plural marking on the noun, 343 (94.8\%) also contained plural marking on the verb. The proportion of cases with plural marking on the verb that also contained plural marking on the noun was smaller (83.7\%). The same asymmetry manifests itself in the responses to the picture description task, though to a somewhat lesser extent, $87.4 \%$ vs. $80.4 \%$.

In both experiments, this asymmetry was mostly driven by responses to the Two condition. Responses to the Two condition of the translation experiment associated plural marking on the noun with covarying plural marking on the verb in 133 out of 140 cases $(95.0 \%)$. Plural marking on the verb occurred with plural marking on the noun in only $70.7 \%$ of all cases. In the Two condition of the picture description task, the distribution was $88.3 \%$ vs. $69.4 \%$. In contrast, the asymmetry did not manifest itself in the responses to the Many condition. For instance, in the translation study, nominal plural marking co-occurred with verbal plural marking $95 \%$ of all times and verbal plural marking with nominal plural marking $95.4 \%$ of times. For the picture descriptions study, the proportions are $86.9 \%$ vs. $89 \%$.

One possible explanation of this asymmetry attributes it to left dislocations (cf. Section 2). Since the left-dislocated position (LDP) is outside the clause, it permits an anaphoric relationship between cross-reference markers and cross-referenced RPs. In this environment, cross-reference markers and cross-referenced RPs are merely required to be semantically compatible in terms of the features they express, rather than to express the same features ('anaphoric agreement' as defined by Bresnan \& Mchombo 1987, as opposed to the 'grammatical agreement' inside the clause). And since it is the cross-reference markers that saturate the head's argument positions under anaphoric agreement, the cross-reference markers might be expected to be more likely than the cross-referenced RPs to reflect the cardinality of the set of referents of the arguments. This hypothesis remains to be tested. ${ }^{17}$ If borne out, it would entail that number agreement inside the clause approaches the kind of production frequencies known from languages in which it is obligatory and in which the absence of agreement is considered an error (see references to the literature on agreement production cited above).

\footnotetext{
${ }^{17}$ We have not (yet) coded the data for the syntactic position of the cross-referenced RP.
} 


\section{Conclusions}

Van Valin's early (1977) insight that cross-reference markers saturate the syntactic argument positions of heads in head-marking languages and that such languages consequently lack traditional subject-external VPs is one of the foundational ideas of RRG. Ramifications of this idea can be found throughout the theory. It particularly influenced the notion of the verbal core, a cornerstone of the Layered Structure of the Clause model, and the treatment of predication and grammatical relations as independent of phrase structure.

Yet, the question of the relation between cross-reference markers and crossreferenced RPs has always remained somewhat of a challenge. To the extent that cross-referenced RPs occur outside the clause, this relation is straightforwardly anaphoric. In mainstream Generative Grammar, this situation is often assumed to be canonical in head-marking (e. g. Jelinek 1984, Baker 1991, 1996, Pensalfini 2004). But, as pointed out by Simpson (1991), Austin \& Bresnan (1996), and Van Valin (2013), inter alia, this assumption is in many cases unwarranted: many languages clearly allow the co-occurrence of cross-reference markers with crossreferenced RPs inside the clause.

A number of alternative analyses have been proposed for the relation between cross-reference markers and cross-referenced clause-mate RPs. A traditional view that can be traced back as far as Humboldt (1836) is that the two stand in an appositive relation. But as Lehmann (1985) observes, this view seems to presuppose an understanding of apposition that so far nobody has been able to formally explicate.

Van Valin (1985) instead treats clause-mate cross-referenced RPs as restrictive modifiers of the cross-reference markers and as occupying the same position as clause-level adjuncts. However, the morphological and distributional properties of cross-referenced RPs are clearly distinct from those of bona fide adjuncts, rendering this analysis rather ad hoc within more recent versions of the LSC model. Van Valin (2013) instead suggests that cross-referenced RPs may be hosted in a previously unrecognized 'Extra-Core Slot' position, which does not belong to the clausal periphery, but is nonetheless directly dominated by the clause.

Lastly, a fourth option was prominently proposed by Bresnan \& Mchombo (1987). On this proposal, there are two kinds of cross-reference markers. Those that exclude clause-mate cross-referenced RPs are incorporated pronominal ar- 
guments, whereas those that can co-occur with clause-mate cross-referenced RPs are ambiguous between incorporated pronominal arguments and agreement markers with the PRO-drop property of Latin and Roman subject agreement markers (Perlmutter 1971, Jaeger \& Gerassimova 2002, inter alia), realizing the arguments of the head in the absence of a clause-mate cross-referenced RP, but expressing agreement with it in its presence.

In this paper, we have presented two sources of evidence that we think argue in favor of an ambiguous, PRO-drop-style analysis of cross-reference marking in Yucatec Maya, a purely head-marking language. First, the possibility of cross-referenced clause-mate RPs to occur between the two nuclei of a core cosubordination discourages the analysis of these RPs as direct daughters of the clause, given the general absence of discontinuous syntactic projections in the language. Secondly, the results of two production experiments suggest that speakers prefer to mark the number of an argument on both the head and crossreferenced RPs. We argue that, given that plural marking is optional in Yucatec, this distribution is more in line with a PRO-drop analysis than with a core-external analysis of the cross-referenced RPs.

Neither of the arguments we have advanced here is cut-and-dried. While the distributional evidence from core cosubordinations in Yucatec seems hard to reconcile with an analysis of the Extra-Core Slot (ECS) of Van Valin (2013) as an immediate daughter of the clause, the data is in fact consistent with an alternative treatment of the ECS as adjoined to the core. The relative merits of such a core-layer adjunction analysis over an ambiguous analysis would have to be carefully examined.

As for our production data, while it is suggestive of syntactic agreement, it does not show a categorical pattern. It may be that richer coding of the data and a more sophisticated analysis will in fact unearth something more approaching a categorical distribution. It is also conceivable that syntactic agreement in optionally marked functional categories never approaches a categorical distribution. This is unclear simply because the production of agreement in optionally marked categories has rarely ever been studied to date (one recent partial exception is Lorimor 2007 on Lebanese Arabic). Similarly, it is possible that the covariation between verbal and nominal plural marking we observed in our production data is not in fact the result of syntactic agreement, but is driven by other factors that are not yet well understood. 
Thus, the debate over the relation between head-marking and agreement will continue, and it seems impossible to predict what theoretical innovations it may yet inspire. Meanwhile, beyond the question of the relation between head-marking and agreement, we hope that our study illustrates the potential for traditional syntactic analysis and the analysis of variation in experimental or corpus data to inform one another - including in research on indigenous languages in the field.

\section{References}

Aissen, J. 1987. Tzotzil clause structure. Dordrecht, Netherlands: Reidel Publishing. Aissen, J. 1999. Agent focus and inverse in Tzotzil. Language 75: 451-485.

Austin, P. \& J. Bresnan. 1996. Non-configurationality in Australian Aboriginal languages. Natural Language and Linguistic Theory 14: 215-268.

Baker, M. 1991. On some subject/object asymmetries in Mohawk. Natural Language and Linguistic Theory 9: 537-576.

Baker, M. 1996. The polysynthesis parameter. Oxford: Oxford University Press.

Bloomfield, L. 1933. Language. New York, NY: Henry Holt.

Boas, F. 1911. Linguistics and ethnology. In F. Boas (ed.), Handbook of American Indian languages, 59-73. Washington, DC: Smithsonian Institution.

Bock, J. K. \& K. M. Eberhard. 1993. Meaning, sound and syntax in English number agreement. Language and Cognitive Processes 8: 57-99.

Bock, J. K. \& C. A. Miller. 1991. Broken agreement. Cognitive Psychology 23(1): 45-93.

Bock, J. K. \& K. M. Eberhard. 1993. Meaning, sound and syntax in English number agreement. Language and Cognitive Processes 8: 57-99.

Bohnemeyer, J. 1998. Time relations in discourse: Evidence from Yukatek Maya. Tilburg University dissertation.

Bohnemeyer, J. 2002. The grammar of time reference in Yukatek Maya. Munich: LINCOM.

Bohnemeyer, J. 2004. Split intransitivity, linking, and lexical representation: the case of Yukatek Maya. Linguistics 42(1): 67-107.

Bohnemeyer, J. 2009a. Linking without grammatical relations in Yucatec: Alignment, extraction, and control. In Y. Nishina, Y. M. Shin, S. Skopeteas, E. Verhoeven \& J. Helmbrecht (eds.), Issues in functional-typological linguistics and 


\section{References}

language theory: A Festschrift for Christian Lehmann on the occasion of his 60th birthday, 185-214. Berlin: Mouton de Gruyter.

Bohnemeyer, J. 2009b. Temporal anaphora in a tenseless language. In W. Klein \& P. Li (eds.), The expression of time in language, 83-128. Berlin: Mouton de Gruyter.

Bohnemeyer, J. 2012. In the mood for status: Subjunctive and irrealis in Yucatec. Presented at SULA 7: The semantics of under-represented languages in the Americas. Cornell University.

Bohnemeyer, J. \& R. D. Van Valin, Jr. The Macro-Event Property and the layered structure of the clause. Manuscript - University at Buffalo.

Borer, H. 2005. In name only: Structuring sense. Oxford: Oxford University Press.

Bresnan, J. 1982. Polyadicity. In J. Bresnan (ed.), The mental representation of grammatical relations, 149-172. Cambridge, MA: MIT Press.

Bresnan, J. \& S. Mchombo. 1987. Topic, pronoun, and agreement in Chicheŵa. Language 63: 741-782.

Bricker, V. R. 1979. Wh-questions, relativization, and clefting in Yucatec Maya. In L. Martin (ed.), Papers in Mayan linguistics 3, 107-136. Columbia, MO: Lucas Brothers.

Butler, L. K. 2012. Crosslinguistic and experimental evidence for non-number plurals. Linguistic Variation 12(1): 27-56.

Butler, L. K., J. Bohnemeyer \& T. F. Jaeger. 2014. Syntactic constraints and production preferences for optional plural marking in Yucatec Maya. In A. Machicao y Priemer, A. Nolda \& A. Sioupi (eds.), Zwischen Kern und Peripherie: Untersuchungen zu Randbereichen in Sprache und Grammatik [Between core and periphery: Studies on peripheral phenomena in language and grammar], 181-208. Berlin: de Gruyter.

Chomsky, N. 1981. Lectures on Government and Binding. Dordrecht: Foris.

Diesing, M. \& E. Jelinek. 1995. Distributing arguments. Natural Language Semantics 3(2): 123-176.

Dowty, D. R. 1979. Word meaning and Montague Grammar: The semantics of verbs and times in Generative Semantics and Montague's PTQ. Dordrecht: Reidel.

Durbin, M. \& F. Ojeda. 1978. Basic word-order in Yucatec Maya. In N. C. England (ed.), Papers in Mayan linguistics 2, 69-77. Columbia: University of Missouri, Department of Anthropology. 
Foley, W. \& R. D. Van Valin, Jr. 1984. Functional syntax and universal grammar. Cambridge: Cambridge University Press.

Gutiérrez Bravo, R. \& J. Monforte y Madera. 2008. On the nature of unmarked word order in Yucatec Maya. Presented at the 2008 Annual Meeting of the Society for the Study of the Indigenous Languages of the Americas, Chicago.

Gutiérrez Bravo, R. \& J. Monforte y Madera. 2009. Focus, agent focus and relative clauses in Yucatec Maya. In H. Avelino, J. Coon \& E. Norcliffe (eds.), MIT working papers in linguistics 59 (New perspectives in Mayan linguistics), 83-96. Cambridge, MA: Massachusetts Institute of Technology.

Gutiérrez Bravo, R. \& J. Monforte y Madera. La alternancia sujeto inicial/verbo inicial y la teoría de la optimidad (Subject-initial/verb-initial alternation and Optimality Theory). Manuscript - El Colegio de Mexico.

Hale, K. 1983. Warlpiri and the grammar of non-configurational languages. Natural Language and Linguistic Theory 1: 5-74.

Hartsuiker, R. J., H. J. Schriefers, K. Bock \& G. M. Kikstra. 2003. Morphophonological influences on the construction of subject-verb agreement. Memory \& cognition 31(8): 1316-1326.

Humboldt, W. von. 1836. Über die Verschiedenheit des menschlichen Sprachbaues und ihren Einfluss aft die geistige Entwicklung des Menschengeschlects. Berlin: Dümmler.

Jaeger, T. F. \& V. Gerassimova. 2002. Bulgarian word order and the role of the direct object clitic in LFG. In M. Butt \& T. H. King (eds.), Proceedings of the LFG02 Conference. Stanford: CSLI Publications.

Jelinek, E. 1984. Empty categories and non-configurational languages. Natural Language and Linguistic Theory 2: 39-76.

Krämer, M. \& D. Wunderlich. 1999. Transitivity alternations in Yucatec, and the correlation between aspect and argument roles. Linguistics 37: 431-480.

Lambrecht, K. 1994. Information structure and sentence form: Topic, focus, and the mental representations of discourse referents. Cambridge: Cambridge University Press.

Lehmann, C. 1985. On grammatical relationality. Folia Linguistica 19: 67-109.

Lehmann, C. 1991. El hijo prodigo - The prodigal son. Story narrated by Gregorio Vivas and recorded and transcribed by Christian Lehmann with the help of Julio Ek May. Erfurt: Seminar für Sprachwissenschaft, Philosophische Fakultät, University of Erfurt. 


\section{References}

Lehmann, C. 2003. Possession in Yucatec Maya, Second revised edition. ASSidUE Nr. 10, Erfurt: Seminar für Sprachwissenschaft der Universität.

Lewis, M. P. (ed.). 2009. Ethnologue: Languages of the World, Sixteenth edition. Dallas, TX: SIL International. Available online: http:/www.ethnologue.com, accessed December $13^{\text {th }} 2010$.

Lorimor, H. 2007. Conjunctions and grammatical agreement. University of Illinois at Urbana-Champaign, dissertation.

Milewski, T. 1950. La structure de la phrase dans les langues indigenes de l'Amérique du Nord. In T. Milewski (ed.), Études typologiques sur les langues indigenes de l' Amérique, 7-101. Kraków, Poland : Polska Akademia Nauk.

Nichols, J. 1986. Head-marking and dependent-marking grammar. Language 62: 56-119.

Norcliffe, E. 2009. Head-marking in usage and grammar: A study of variation and change in Yucatec Maya. Stanford University dissertation.

Pensalfini, R. 2004. Towards a typology of non-configurationality. Natural language and linguistic theory 22: 359-408.

Perlmutter, D. 1971. Deep and surface structure constraints in syntax. New York: Holt Rinehart Winston.

PHLI. 2009. Perfil sociodemográfico de la población que habla lengua indígena [socio-demographic profile of the speakers of indigenous languages]. Aguascalientes: Instituto Nacional de Estadística y Geografía. Available online: http://www.inegi.org.mx/prod_serv/contenidos/espanol/bvinegi/productos/c ensos/poblacion/poblacion_indigena/leng_indi/PHLI.pdf, accessed June $23^{\text {rd }}$ 2011.

Shimojo, M. 1995. Focus structure and morphosyntax in fapanese: wa and ga, and word order flexibility. University at Buffalo dissertation.

Simpson, J. 1991. Warlpiri morpho-Syntax: A lexicalist approach. Dordrecht: Kluwer.

Skopeteas, S. \& E. Verhoeven. 2005. Postverbal argument order in Yucatec Maya. Language typology \& universals 58(4): 347-373.

Skopeteas, S. \& E. Verhoeven. 2009. Distinctness effects on VOS order: Evidence from Yucatec Maya. In H. Avelino, J. Coon \& E. Norcliffe (eds.), MIT working papers in linguistics 59 (New perspectives in Mayan linguistics), 135-152.

Skopeteas S. \& E. Verhoeven. Licensing focus constructions in Yucatec Maya. Manuscript - Bielefeld University. 
Talmy, L. 2000. Toward a cognitive semantics. Volume I. Cambridge, MA: MIT Press.

Tonhauser, J. 2003. F-constructions in Yucatec Maya. In J. Anderssen, P. Menéndez Benito \& A. Werle, (eds.), Proceedings of SULA 2, 203-223. Amherst, MA: GLSA.

Tonhauser, J. 2007. Agent focus and voice in Yucatec Maya. Proceedings of the 39th meeting of the Chicago Linguistic Society, 540-558. Chicago: Chicago Linguistic Society.

Tonhauser, J. The syntax and semantics of Yucatec Mayan focus constructions. Manuscript - The Ohio State University.

Van Valin, R. D., Jr. 1977. Aspects of Lakhota syntax. University of California, Berkeley, dissertation.

Van Valin, R. D., Jr. 1985. Case marking and the structure of the Lakhota clause. In J. Nichols \& T. Woodbury (eds.), Grammar inside and outside the clause, 363-413. Cambridge: Cambridge University Press.

Van Valin, R. D., Jr. (ed.). 1993. Advances in role and reference grammar. Amsterdam: Benjamins.

Van Valin, R. D., Jr. 2005. Exploring the syntax-semantics interface. Cambridge: Cambridge University Press.

Van Valin, R. D., Jr. 2013. Head-marking languages and linguistic theory. In B. Bickel, L. A. Grenoble, D. A. Peterson, \& A. Timberlake (eds.), Language typology and historical contingency: In honor of Johanna Nichols, 91-123. Amsterdam: John Benjamins.

Van Valin, R. D., Jr. \& W. Foley. 1980. Role and Reference Grammar. In E. A. Moravcsik \& J. R. Wirth (eds.), Current approaches to syntax. Syntax and semantics 13, 329-352. New York: Academic Press.

Van Valin, R. D., Jr. \& R. J. LaPolla. 1997. Syntax. Cambridge: Cambridge University Press.

Vapnarsky, V. 1995. Las voces de las profecías: Expresiones y visiones del futuro en maya yucateco [The voices of the prophesies: Expressions and visions of the future in Yucatec Maya]. Trace 28: 88-105.

Vapnarsky, V. 2013. Is Yucatec Maya an omnipredicative language? Predication, the copula and focus constructions. STUF - Language Typology and Universals 66(1): 40-86. 


\section{References}

Vigliocco, G., Butterworth, B., \& C. Semenza. 1995. Constructing subject-verb agreement in speech: The role of semantic and morphological factors. fournal of Memory and Language 43(2): 186-215.

Villa Rojas, A. 1945. The Maya of East Central Quintana Roo, Mexico. Washington: Carnegie Institution of Washington Publication 559.

Wiltschko, M. 2008. The syntax of non-inflectional plural marking. Natural Language and Linguistic Theory 26: 639-694.

Zavala Maldonado, R. 1993. Clause integration with verbs of motion in Mayan languages. University of Oregon, Master's thesis.

\section{Authors}

Jürgen Bohnemeyer (Corresponding author)

Department of Linguistics

University at Buffalo, The State University of New York

609 Baldy Hall

Buffalo, NY 14260

jb77@buffalo.edu

Lindsay K. Butler

Communication Sciences and Disorders, The Pennsylvania State University

T. Florian Jaeger

Department of Brain and Cognitive Sciences, University of Rochester 
